\title{
Decline in FEV1 related to smoking status in individuals with severe $\alpha_{1}$-antitrypsin deficiency (PiZZ)
}

\author{
E. Piitulainen*, S. Eriksson**
}

\begin{abstract}
Decline in FEVI related to smoking status in individuals with severe $\alpha_{1}$-antitrypsin deficiency (PiZZ). E. Piitulainen, S. Eriksson. (C)ERS Journals Ltd 1999.

ABSTRACT: Severe $\alpha_{1}$-antitrypsin (AAT) deficiency predisposes to emphysema development. Highly variable rates of decline in lung function are reported in PiZZ individuals. The annual decline in forced expiratory volume in one second (FEV1; $\triangle F E V 1)$ was analysed in relation to smoking status in a cohort of 608 adult PiZZ individuals included in the Swedish national AAT deficiency register.

$\triangle F E V 1$ was analysed in 211 never-smokers, in 351 exsmokers, and in 46 current smokers after performing at least two spirometries during a follow-up time of $1 \mathrm{yr}$ or longer (median 5.5 yrs, range 1-31).

The adjusted mean $\triangle F E V 1$ in never-smokers was $47 \mathrm{~mL} \cdot \mathrm{yr}^{-1}(95 \%$ confidence interval (CI) 41-53 mL.yr $\left.{ }^{-1}\right), 41 \mathrm{~mL} \cdot \mathrm{yr}^{-1}\left(95 \%\right.$ CI 36-48 $\left.\mathrm{mL} \cdot \mathrm{yr}^{-1}\right)$ in exsmokers, and 70 $\mathrm{mL} \cdot \mathrm{yr}^{-1}\left(95 \% \mathrm{CI} 58-82 \mathrm{~mL} \cdot \mathrm{yr}^{-1}\right)$ in current smokers. A dose-response relationship was found between cigarette consumption and $\triangle F E V 1$ in current smokers and exsmokers. In never-smokers, a greater $\triangle F E V 1$ was found after 50 yrs of age than before. No sex differences were found in $\triangle F E V 1$.

In conclusion, among PiZZ individuals, the change in forced expiratory volume in one second is essentially the same in never-smokers and exsmokers. Smoking is associated with a dose-dependent increase in the change in forced expiratory volume in one second.

Eur Respir J 1999; 13: 247-251.
\end{abstract}

\author{
*Dept of Lung Medicine and **Dept of \\ Medicine, Lund University, University \\ Hospital, Malmö, Sweden. \\ Correspondence: E. Piitulainen \\ Dept of Lung Medicine \\ University Hospital \\ Malmö \\ S-205 02 Malmö \\ Sweden \\ Fax: 4640336225 \\ Keywords: $\alpha_{1}$-antitrypsin deficiency \\ lung function decline \\ smoking \\ smoking cessation
}

Received: March 231998 Accepted after revision September 91998

Supported by grants from the Swedish National Heart and Lung Association and the Förenade Liv Mutual Group Life Insurance Company, Stockholm, Sweden.
Severe $\alpha_{1}$-antitrypsin (AAT) deficiency predisposes to pulmonary emphysema [1-3], chronic liver disease [4] and rarely to vasculitic disorders [5]. Several cross-sectional analyses have shown a decreased lung function at an early age in current and exsmokers [1-3]. Smoking is therefore the main risk factor for emphysema development in PiZZ individuals, but lung function impairment is also found in elderly never-smoking PiZZ individuals [6].

In longitudinal studies, the rate of decline in lung function is commonly assessed by annual decline in forced expiratory volume in one second $(\triangle \mathrm{FEV} 1)$, expressed as $\mathrm{mL} \cdot \mathrm{yr}^{-1}$ [7]. In studies of individuals with severe AAT deficiency (PiZZ), highly variable $\triangle \mathrm{FEV} 1$ values are reported [8-13]. Earlier studies, apart from being small, have predominantly included ex- and current smokers, and the majority of the participants have been identified because of respiratory symptoms. As only few never-smokers have been studied, the natural course of the decline in lung function in severe AAT deficiency is still unknown. The only existing prospective study of AAT deficiency was started in Sweden 1972-1974 [14] by a neonatal screening programme of 200,000 newborns, where 127 PiZZ and two PiZ0 individuals were identified. This cohort has been followed for two decades [15], but several decades are still needed before the cohort will help to elucidate the natural history of severe AAT deficiency.

Replacement therapy with purified human AAT has been available for 10 yrs [16]. Controlled clinical trials of the efficacy of replacement therapy on lung function have, however, not been carried out so far. Recently, a comparison of the annual decline in lung function between German treated and Danish untreated PiZZ individuals has been published [17]. With access to only limited data on the natural course of decline in lung function in PiZZ individuals, such results are difficult to interpret [18].

Owing to the lack of epidemiological studies in adults, national registers of AAT deficiency may facilitate studies of natural history, clinical features and lung function in AAT-deficient individuals $[6,13,19]$. The Swedish AAT deficiency register was established in 1991. All physicians who have detected an individual aged $\geq 18$ yrs with PiZZ, PiZ0 or Pi00 phenotypes living in Sweden are encouraged to invite their patient to participate in the register. After inclusion, the subjects are followed up by their attending physician, and the results are reported to the register by questionnaires [6]. In October 1997, 889 individuals were included in the register. The adult population in Sweden being approximately seven million, the register contains about $20 \%$ of the expected total number of adult PiZZ individuals in Sweden (prevalence 1 in 1,600 [14]). In the Swedish register, $30 \%$ of the PiZZ individuals are iden-tified by extrapulmonary symptom or disease, and $25 \%$ by screening/family studies. Only $45 \%$ of the register participants are identified through respiratory symptoms. This is a smaller figure than for other national registers [13, 19].

In a large cohort of PiZZ individuals, the $\triangle F E V 1$ related to smoking status was analysed in this study. 


\section{Patients and methods}

\section{Patients}

All subjects were included in the Swedish national AAT deficiency register [6]. They were $>20$ yrs old and had performed at least two spirometries over a $1-y r$ period or longer. In 32 lung-transplanted patients, only the test results before the operation were included in the analysis. Individuals from the neonatal screening programme [14], and subjects given replacement therapy with human AAT, were excluded.

Eighteen of the 889 PiZZ individuals were $<20$ yrs old, 31 were on replacement therapy, and 84 had been identified by the neonatal screening programme [14]. In 114 subjects, only one spirometry was available. Thirtyfour smokers, who stopped smoking during the follow-up time, were excluded. The study group included 608 PiZZ individuals (211 never-smokers, 351 exsmokers and 46 current smokers). Thirty-two per cent of the never-smokers, $64 \%$ of the exsmokers, and $40 \%$ of the current smokers were identified because of respiratory symptoms.

\section{The questionnaire}

The register is administered via a questionnaire described in detail elsewhere [6]. It contains two parts: one to be answered by the attending physician and one to be answered by the PiZZ individual. The following data obtained at the time of inclusion in the register were analysed: results of the spirometry, if any, performed before inclusion in the register; the spirometry at time of inclusion in the register; and smoking habits, regular smoking, age at start and stop, average number of daily cigarettes. At follow-ups, the results of the actual spirometry were analysed.

\section{Lung-function tests}

Spirometry including forced expiratory volume in one second (FEV1) and vital capacity (VC) were performed at the patients' local hospital. Measurements were made in accordance with European recommendations [20]. Spirometric data are expressed in litres, and as a percentage of predicted normal values [21]. $\triangle \mathrm{FEV} 1$ is expressed as $\mathrm{mL} \cdot \mathrm{yr}^{-1}$. Only prebronchodilator values were analysed, because reversibility tests to bronchodilator were not consistently performed.

\section{Pi typing}

All Pi-phenotyping diagnoses were performed by isoelectric focusing at the Department of Clinical Chemistry, University Hospital, Malmö [22]. Without family investigation or deoxyribonucleic acid (DNA)-based analysis, phenotypes PiZ0 and PiZZ cannot be distinguished, but no subjects with phenotype Pi00 were identified. PiZ0 is very infrequent in the population [14].

\section{Statistical analysis}

Covariance analysis was used to compare the continuous variables at entry with age as covariate. $\triangle \mathrm{FEV} 1$ was analysed by random effects modelling [23, 24], which included FEV1 (L) as the dependent variable, age, FEV1 ( $\%$ of the predicted value) at entry, and follow-up time as covariates, sex and smoking status as fixed parameters, and the individual patients as random effects parameters. A pvalue $<0.05$ was considered significant.

\section{Results}

\section{Characteristics, lung function and $\triangle F E V I$}

Of the 608 PiZZ individuals, 309 were males. In the series as a whole, the meansd age was $45 \pm 13$ yrs at baseline. The mean \pm SD FEV1 was $68 \%$ predicted, the mean VC $85 \%$ pred, and the mean ratio FEV1/VC was $60 \pm 21 \%$. The median follow-up time was 5.5 yrs (range 1.0-31). In $61 \%$ (368 of 608 ) of the subjects, the first spirometry was performed before inclusion in the register. The overall mean (SD) $\triangle \mathrm{FEV} 1$ was 48 (79) $\mathrm{mL} \cdot \mathrm{yr}^{-1}$.

Characteristics, lung function at entry and follow-up time by smoking status are shown in table 1 . The current smokers were younger than the ex- and never-smokers (table 1). The mean FEV1 (\% pred), and mean ratio FEV1/VC (\%) at baseline were significantly better in never-smokers than in exsmokers $(\mathrm{p}<0.001$, after age correction) and in current smokers $(\mathrm{p}<0.01$; table 1$)$.

The median number of spirometries was three (range 27 ) in never-smokers and current smokers, and four (range $2-7$ ) in exsmokers. The adjusted mean $\triangle F E V 1$ did not differ significantly between the never-smokers and exsmokers, whereas it was significantly larger in the current smokers ( $p<0.001$; fig. 1 , table 2$)$, There were no significant sex differences in $\triangle \mathrm{FEV} 1$ in any smoking subgroup. $\triangle \mathrm{FEV} 1$ by smoking status was essentially the same in subjects identified because of respiratory symptoms and in those identified because of extrapulmonary symptoms or screening/family studies (data not shown).

To determine whether $\triangle \mathrm{FEV} 1$ was influenced by the large range of follow-up time, it was separately analysed

Table 1. - The mean (SD) for age, lung function and cigarette consumption at entry, and the median (range) for follow-up related to smoking status

\begin{tabular}{|c|c|c|c|}
\hline & $\begin{array}{l}\text { Never- } \\
\text { smokers } \\
\mathrm{n}=211\end{array}$ & $\begin{array}{l}\text { Exsmokers } \\
\qquad \mathrm{n}=351\end{array}$ & $\begin{array}{c}\text { Current } \\
\text { smokers } \\
n=46\end{array}$ \\
\hline Male/Female & $97 / 114$ & $195 / 156$ & $17 / 29$ \\
\hline Age yrs & $43(17)$ & $45(11)$ & $39(11)$ \\
\hline FEV1 L & $3.1(13)$ & $2.1(1.3)$ & $2.5(1.3)$ \\
\hline VC L & $4.2(1.4)$ & $3.8(1.4)$ & $3.8(1.4)$ \\
\hline FEV1/VC \% & 73 (17) & $53(20)^{* * *}$ & $64(21)^{* *}$ \\
\hline FEV1 \% pred & $87(26)$ & $59(32)^{* * *}$ & $67(28)^{* *}$ \\
\hline VC \% pred & $91(19)$ & $82(23)^{* * *}$ & $83(21)$ \\
\hline $\begin{array}{c}\text { Daily number } \\
\text { of cigarettes }\end{array}$ & - & $14(9)$ & $16(8)$ \\
\hline $\begin{array}{l}\text { Number of } \\
\text { pack-yrs } \\
\text { Median (range) }\end{array}$ & - & $15(13)$ & $22(15)$ \\
\hline $\begin{array}{l}\text { Median (range) } \\
\text { follow-up yrs }\end{array}$ & $4.5(1.0-27)$ & $6.5(1.0-31)$ & $4.2(1.0-30)$ \\
\hline
\end{tabular}
ume in one second. VC: vital capacity. 


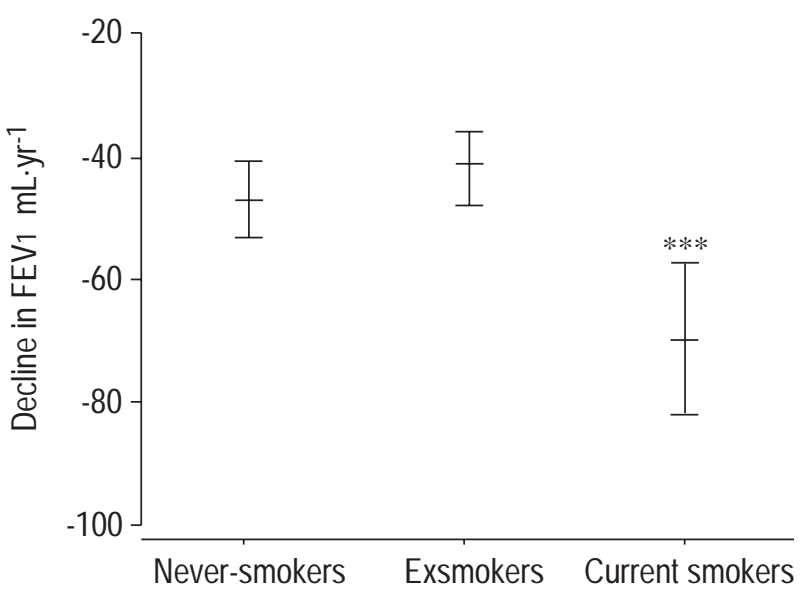

Fig. 1. - Mean annual decline in forced expiratory volume in one second $(\triangle \mathrm{FEV} 1)$ with $95 \%$ confidence intervals in 211 never-smokers, 351 exsmokers and 46 current smokers. $* * *: \mathrm{p}<0.001$, compared with never- and exsmokers.

by smoking status in the subgroup followed up for $\geq 5$ yrs. The adjusted mean $\triangle F E V 1$, was $48 \mathrm{~mL} \cdot \mathrm{yr}^{-1}(95 \%$ confidence interval (CI) $42-54 \mathrm{~mL} \cdot \mathrm{yr}^{-1}$ ) in the 86 never-smokers, $40 \mathrm{~mL} \cdot \mathrm{yr}^{-1}\left(95 \% \mathrm{CI} 34-46 \mathrm{~mL} \cdot \mathrm{yr}^{-1}\right)$ in the 218 exsmokers, and $70 \mathrm{~mL} \cdot \mathrm{yr}^{-1}\left(95 \%\right.$ CI $\left.56-85 \mathrm{~mL} \cdot \mathrm{yr}^{-1}\right)$ in the 20 current smokers.

To study the effect of ageing on the rate of decline in FEV1, $\triangle$ FEV1 was also analysed by smoking status in subjects who had performed at least two spirometries before and after the age of $50 \mathrm{yrs}$. In never-smokers $\triangle \mathrm{FEV} 1$ was on average $23 \mathrm{~mL} \cdot \mathrm{yr}^{-1}(95 \% \mathrm{CI} 9-36 \mathrm{~mL})$ larger after 50 yrs of age than before $(p<0.01)$. Such an increase could not be seen in current smokers or exsmokers.

\section{Dose-response relationships for smoking and $\triangle F E V 1$}

In current smokers, the quantitative effect was assessed by relating the daily cigarette consumption since the start of smoking, median 15 cigarettes.day ${ }^{1}$, to the $\triangle \mathrm{FEV} 1$. The mean $\triangle F E V 1$ was on average $36 \mathrm{~mL} \cdot \mathrm{yr}^{-1}(95 \%$ CI $24-48$ $\mathrm{mL} \cdot \mathrm{yr}^{-1}$ ) greater in subjects smoking $\geq 15$ cigarettes $\cdot$ day $^{-1}$ than in those smoking $<15$ cigarettes day $^{-1}(p<0.01)$. In exsmokers, no significant relationship was found between the median daily cigarette consumption and $\triangle \mathrm{FEV} 1$.

In exsmokers, the same relationship was also assessed by the total lifetime cigarette consumption, i.e. the number of pack-yrs. The median number of pack-yrs being 14, $\triangle \mathrm{FEV} 1$ was compared between a subgroup with an equal or higher cigarette consumption than the median $(\geq 14$ pack-yrs) and a subgroup with lower cigarette consumption than the median $(<14$ pack-yrs $)$. The mean \pm SD ages in the subgroups were $49 \pm 9$ and $46 \pm 13$ yrs, respectively. The mean duration between smoking cessation and baseline spirometry was $5 \pm 6$ yrs in the subgroup with $\geq 14$ pack-yrs as opposed to $11 \pm 10$ yrs in the subgroup with $<14$ packyrs. $\triangle \mathrm{FEV} 1 \mathrm{was}$ a mean of $20 \mathrm{~mL} \cdot \mathrm{yr}^{-1}(95 \%$ CI $11-29$ $\mathrm{mL} \cdot \mathrm{yr}^{-1}$ ) higher in the $\geq 14$ pack-yrs subgroup than in the $<14$ pack-yrs subgroup $(\mathrm{p}<0.01)$.

\section{Discussion}

The present study shows the annual $\triangle \mathrm{FEV} 1$ to be similar in never-smokers and in exsmokers with severe AAT deficiency (PiZZ). In current smokers, $\triangle \mathrm{FEV} 1$ is significantly larger.

In population studies of healthy adult never-smokers, FEV1 declines slowly over time $\left(20-30 \mathrm{~mL} \cdot \mathrm{yr}^{-1}\right)$ with some acceleration with age $[7,25,26]$. In smokers developing chronic obstructive pulmonary disease (COPD), the rate of decline in FEV1 is larger, but after smoking cessation, the decline slows to the normal rate [7, 25-29]. The results of this study indicate that in PiZZ individuals, the pattern of decline in FEV1 related to smoking status is similar to that in the general population, but in PiZZ subjects, the rate of decline is accelerated. In the present study, the length of follow-up was short in many cases. Half of the subjects were followed-up for $\geq 5 \mathrm{yrs}$. However, a separate analysis of $\triangle F E V 1$ by smoking status showed identical values in the subgroup with a long follow-up ( $\geq 5$ yrs) and the whole study population, most likely reflecting the statistical approach used (random effects modelling) where the follow-up time is included as a covariate.

In never-smokers, the mean $\triangle \mathrm{FEV} 1$ was found to be 47 $\mathrm{mL} \cdot \mathrm{yr}^{-1}$, whereas earlier longitudinal studies have shown larger declines [10-13]. Table 2 summarizes $\triangle F E V 1$ related to smoking status in this and in previously published longitudinal studies of individuals with severe AAT deficiency. The authors suggest that in never-smoking PiZZ individuals, $\triangle \mathrm{FEV} 1$ has been overestimated, most likely due to the small number of never-smokers included in the previous longitudinal studies [10-13]. It is probable that never-smoking PiZZ individuals usually have well-preserved lung function and lack respiratory symptoms, explaining why only a few of them have been identified in earlier series of PiZZ individuals [8-13]. In the present

Table 2. - The annual decline of forced expiratory volume in one second $\left(\Delta \mathrm{FEV} 1 ; \mathrm{mL} \cdot \mathrm{yr}^{-1}\right)$ related to smoking habits in the present study, and in previous longitudinal studies of PiZZ individuals

\begin{tabular}{|c|c|c|c|c|c|c|}
\hline \multirow[b]{2}{*}{ First author [Ref.] } & \multicolumn{2}{|c|}{ Never-smokers } & \multicolumn{2}{|r|}{ Exsmokers } & \multicolumn{2}{|c|}{ Current smokers } \\
\hline & $\mathrm{n}$ & $\Delta \mathrm{FEV}_{1}$ & $\mathrm{n}$ & $\Delta \mathrm{FEV} 1$ & $\mathrm{n}$ & $\Delta \mathrm{FEV}_{1}$ \\
\hline Present study & 211 & 47 (95\% CI 41-53) & 351 & $41(95 \%$ CI $36-48)$ & 46 & $70(95 \%$ CI $58-82)$ \\
\hline $\mathrm{J}_{\text {ANUS }}[10]$ & 7 & $80 \pm 38(\mathrm{SEM})$ & 8 & $61 \pm 43$ & 6 & $316 \pm 43$ (SEM) \\
\hline HutchINSON [11] & 13 & $66 \pm 55(\mathrm{sD})$ & 44 & $44 \pm 56$ (SD) & 25 & $67 \pm 46(\mathrm{SD})$ \\
\hline Wu [12] & 18 & $61 \pm 100(\mathrm{SD})$ & 22 & $81 \pm 70$ (SD) & 40 & $61 \pm 170(\mathrm{SD})$ \\
\hline SEERSholm [13] & 18 & $86 \pm 107(\mathrm{sD})$ & 100 & $58 \pm 80(\mathrm{SD})$ & 43 & $132 \pm 105(\mathrm{SD})$ \\
\hline SeERSholm [17]* & - & & 198 & $53(95 \%$ CI $48-58)$ & - & - \\
\hline SEersholm $[17]^{* *}$ & - & & 97 & 75 (95\% CI 63-87) & - & - \\
\hline
\end{tabular}

*: German exsmokers treated by replacement therapy with human purified $\alpha_{1}$-antitrypsin [17]; **: Danish untreated exsmokers [17]. CI: confidence interval. 
study, the majority of the never-smokers $(68 \%)$ were identified for other reasons than respiratory symptoms, and thereby, a large number of never-smokers could be studied.

This larger study confirms the findings of the authors earlier cross-sectional study of never-smoking PiZZ individuals, in whom lung function impairment was seen above the age of 50 yrs [6]. The well-preserved lung function in never-smoking PiZZ individuals complies with the results published by SEERSHOLM et al. [30] who found a normal survival rate in never-smoking PiZZ individuals identified by family studies.

Exsmokers had a similar $\triangle \mathrm{FEV} 1$ to never-smokers (table 2) indicating that, in PiZZ individuals, as in the general population, $\triangle F E V 1$ reverts to the same level as in never-smokers after smoking cessation. SEERSHOLM et al. [13] noticed a similar trend as in the present study when comparing current and exsmokers, but their results in never-smokers were not borne out by the present findings, a reflection of their small number of never-smokers (table 2) [13]. However, the lower $\triangle \mathrm{FEV} 1$ in exsmokers, as compared to current smokers seen both in this and in the Danish study [13], is well in accordance with the improved survival rate in subjects who have stopped smoking, observed in another study of PiZZ individuals [31].

In the present study, a lower $\triangle \mathrm{FEV} 1$ in exsmokers was found than in previous studies (table 2). The recently published German-Danish study on the putative effect of replacement therapy with human purified AAT on $\triangle \mathrm{FEV} 1$ showed a larger $\triangle F E V 1$ both in German treated and in Danish untreated exsmokers [17] than in the present exsmokers (table 2). Several factors may have contributed to the differences in results. Prebronchodilator values of FEV1 were analysed in this study, while postbronchodilator values were analysed in the German patients, but it is unknown whether pre- or postbronchodilator values were analysed in the Danish patients. The number of exsmokers was greater in the present study than in the GermanDanish study (table 2). The mean age at entry was similar in both studies, but the minimum age in the latter was higher than in these patients. Furthermore, the patients were recruited to the studies in very different ways. However, a subgroup analysis was performed in exsmokers in the present study identified by respiratory symptoms with an initial FEV1 31-65\% pred, which should be comparable with the corresponding stratified subgroups of the German treated and Danish untreated patients. In this subgroup analysis, the mean $\triangle F E V 1$ of $44 \mathrm{~mL} \cdot \mathrm{yr}^{-1}(95 \%$ CI 35-91 mL-yr-1) was lower than in the German treated $\left(61.8 \mathrm{~mL} \cdot \mathrm{yr}^{-1}\right)$ and the Danish untreated patients $(82.8$ $\left.\mathrm{mL} \cdot \mathrm{yr}^{-1}\right)$ [17]. The discrepancy between the present results and those of the German-Danish study indicate that a controlled clinical trial is needed to show whether the replacement therapy slows down $\triangle \mathrm{FEV} 1$.

In current smokers, a clear dose-response relationship was found between cigarette consumption and $\triangle \mathrm{FEV} 1, \mathrm{a}$ finding that is in agreement with population-based studies $[7,25]$. A dose-response relationship was also found between cigarette consumption and $\triangle \mathrm{FEV} 1$ in exsmokers. The exsmokers with a cigarette consumption $\geq 14$ pack-yrs had stopped smoking later than those with a cigarette consumption $<14$ pack-yrs, indicating that $\triangle \mathrm{FEV} 1$ was influenced either by the time elapsed after smoking cessation or by the number of pack-yrs [26]. In the Lung Health Study, an initial increase of postbronchodilator FEV1 was found after smoking cessation [27]. The authors suggest, therefore, that in exsmokers, $\triangle \mathrm{FEV} 1$ was predominantly influenced by the number of pack-yrs rather than the time elapsed after smoking cessation.

The history of lower respiratory tract infections [5] and occupational exposure to airway irritants [6] are suggested to influence lung function in PiZZ individuals. Possible effects of risk factors other than smoking on $\triangle F E V 1$ were, however, not analysed in the present study. In populationbased studies bronchodilator response, airway hyperreactivity, and treatment with corticosteroids are found to influence $\triangle F E V 1$ in COPD patients $[7,28,29]$. Because reversibility test results were reported in a minority of the subjects, only prebronchodilator values of FEV1 were analysed. Consequently, it was not possible to study whether $\triangle \mathrm{FEV} 1$ was correlated to bronchodilator response. Neither corticosteroid nor other treatments were taken into consideration. Further studies are needed to elucidate which other factors than smoking may influence $\triangle F E V 1$ in PiZZ individuals.

In conclusion, subjects with a severe $\alpha_{1}$-antitrypsin deficiency have a steeper decline in forced expiratory volume in one second than is found in the general population. However, the decline in forced expiratory volume in one second may have been overestimated in previous studies based on a large proportion of patients identified by respiratory symptoms. The decline in forced expiratory volume in one second is similar in never-smokers and exsmokers, as is the case in the general population.

\footnotetext{
Acknowledgements. The authors thank L. Rubin for secretarial assistance, J-A.Nilsson for statistical service, B.G. Simonsson, B. Midgren for scrutinizing the manuscript, and also all the Swedish physicians reporting data to the Swedish AAT deficiency register.
}

\section{References}

1. Eriksson S. Studies in alpha1-antitrypsin deficiency. Acta Med Scand 1965; 432 (Suppl.): 1-85.

2. Larsson C. Natural history and life expectancy severe alpha ${ }_{1}$-antitrypsin deficiency, Pi Z. Acta Med Scand 1978; 204: 345-351.

3. Silverman KE, Pierce JA, Province MA, Rao DC, Campbell EJ. Variability of pulmonary function in alpha-1antitrypsin deficiency: clinical correlates. Ann Intern Med 1989; 111: 982-991.

4. Propst A, Propst T, Öfner D, Feichtinger H, Judmaier G, Vogel W. Prognosis and life expectancy in alpha-1antitrypsin deficiency and chronic liver disease. Scand $J$ Gastroenterol 1995; 53: 1108-1112.

5. Mazodier P, Elzouki A-N, Wieslander J, Eriksson S. Systemic necrotizing vasculitides in severe $\alpha_{1}$-antitrypsin deficiency. $Q J$ Med 1996; 89: 599-6110.

6. Piitulainen E, Tornling G, Eriksson S. Effect of age and occupational exposure to airway irritants on lung function in non-smoking individuals with $\alpha_{1}$-antitrypsin deficiency (PiZZ). Thorax 1997; 52: 244-248.

7. Kerstjens HAM, Brand PLP, Postma DS. Risk factors for accelerated decline among patients with chronic obstructive pulmonary disease. Am J Respir Crit Care Med 1996; 154: S266-272.

8. Brantly ML, Paul LD, Miller BH, Falk RT, Wu M, Crystal RG. Clinical features and history of the destructive lung 
disease associated with alpha-1-antitrypsin deficiency of adults with pulmonary symptoms. Am Rev Respir Dis 1988; 138: 327-336.

9. Buist AS, Burrows B, Eriksson S, Mittman C, Wu M. The natural history of air-flow obstruction in PiZ emphysema. Am Rev Respir Dis 1983; 127 (Suppl.): s43-s50.

10. Janus ED, Phillips NT, Carrell RW. Smoking, lung function, and $\alpha_{1}$-antitrypsin deficiency. Lancet $1985 ; 1$ : $152-$ 154.

11. Hutchinson DCS, Tobin MJ, Cooper D, Lowe D. Longitudinal studies in alpha-1-antitrypsin deficiency: a survey by the British Thoracic Society. In: Taylor JC, Mittman C, eds. Pulmonary Emphysema and Proteolysis. New York, Academic Press, 1987; pp. 7-15.

12. $\mathrm{Wu} \mathrm{Mc}$, Eriksson S. Lung function, smoking, and survival in severe alpha-1-antitrypsin deficiency, PiZZ. $J$ Clin Epidemiol 1988; 41: 1157-1165.

13. Seersholm N, Kok-Jensen A, Dirksen A. Decline in FEV1 among patients with severe hereditary $\alpha_{1}$-antitrypsin deficiency type PiZ. Am J Respir Crit Care Med 1995; 152: 1922-1925.

14. Sveger T. Liver disease in alpha $a_{1}$-antitrypsin deficiency detected by screening of 200,000 infants. $N$ Engl J Med 1976; 294: 1316-1321.

15. Sveger T, Piitulainen E, Arborelius M. Lung function in adolescents with $\alpha_{1}$-antitrypsin deficiency. Acta Paediatric 1994; 83: 1170-1173.

16. Wewers MD, Casolaro MA, Sellers SE, et al. Replacement therapy of alpha $a_{1}$-antitrypsin deficiency associated with emphysema. $N$ Engl J Med 1987; 316: 1055-1062.

17. Seersholm N, Wencker M, Banik N, et al. Does $\alpha_{1^{-}}$ antitrypsin augmentation therapy slow the annual decline in FEV1 in patients with severe hereditary $\alpha_{1}$-antitrypsin deficiency? Eur Respir J 1997; 10: 2260-2263.

18. Hutchison DCS, Hughes MD. Alpha-1-antitrypsin replacement therapy: will its efficacy ever be proved? Eur Respir J 1997; 10: 2191-2193.

19. McElvaney NG, Stoller JK, Buist AS, et al. Baseline characteristics of enrollees in the National Heart, Lung and Blood Institute Registry of $\alpha_{1}$-antitrypsin deficiency. Chest 1997; 111: 394-403.

20. Quanjer PH. Standardized lung function testing. Report of the working party on standardization of lung function tests, European Community for Coal and Steel. Bull Eur Physiopathol Respir 1983; 19 (Suppl. 16): 1-95.

21. Berglund E, Birath G, Bjure J, et al. Spirometric studies in normal subjects. I. Forced expirograms in subjects between 7 and 70 years of age. Acta Med Scand 1963; 173: 185-191.

22. Jeppsson JO, Franzén B. Typing of genetic variants of $\alpha_{1^{-}}$ antitrypsin by electrofocusing. Clin Chem 1982; 225: 219-225.

23. Laird NM, Ware JH. Random-effects models for longitudinal data. Biometrics 1982; 38: 964-974.

24. Jennrich RI, Schluchter MD. Unbalanced repeated measures models with structured covariance matrices. Biometrics 1996; 42: 805-820.

25. Fletcher CM, Peto R, Tinker CM, Speizer FE. The natural history of chronic bronchitis and emphysema. An eightyear study of early chronic obstructive lung disease in working men in London. Oxford, Oxford University Press, 1976.

26. Tashkin DP, Clark VA, Coulson AH, et al. The UCLA population studies of chronic obstructive respiratory disease. VIII. Effects of smoking cessation on lung function: a prospective study of a free-living population. Am Rev Respir Dis 1984; 130: 707-715.

27. Anthonisen NR, Connett JE, Altose MD, et al. Effects of smoking intervention and the use of an inhaled anticholinergic bronchodilator on the rate of decline of FEV1. The Lung Health Study. JAMA 1994; 272: 1497-1505.

28. Postma DS, Sluiter HJ. Prognosis of chronic obstructive pulmonary disease: the Dutch experience. Am Rev Respir Dis 1989; 140: S100-S105.

29. Burrows B. The course and prognosis of different forms of chronic airways obstruction in a sample from the general population. N Engl J Med 1987; 317: 1309-1314.

30. Seersholm N, Kok-Jensen A, Dirksen A. Survival of patients with severe $\alpha_{1}$-antitrypsin deficiency. Thorax 1994; 49: 695-698.

31. Seersholm N, Kok-Jensen A. Survival in relation to lung function and smoking cessation in patients with severe hereditary alpha ${ }_{1}$-antitrypsin deficiency. Am J Respir Crit Care Med 1995; 151: 369-373. 